\title{
Strength models of the terrestrial planets and implications for their lithospheric structure and evolution
}

Ikuo Katayama(D)

\begin{abstract}
Knowledge of lithospheric strength can help to understand the internal structure and evolution of the terrestrial planets, as surface topography and gravity fields are controlled mainly by deformational features within the lithosphere. Here, strength profiles of lithosphere were calculated for each planet using a recently updated flow law and taking into account the effect of water on lithospheric deformation. Strength is controlled predominantly by brittle deformation at shallow depths, whereas plastic deformation becomes dominant at greater depths through its sensitivity to temperature. Incorporation of Peierls creep, in which strain rate is exponentially dependent on stress, results in the weakening of plastic strength at higher stress levels, and the transition from brittle to ductile deformation shifts to shallower depths than those calculated using conventional power-law creep. Strength in both the brittle and ductile regimes is highly sensitive to the presence of water, with the overall strength of the lithosphere decreasing markedly under wet conditions. The markedly low frictional coefficient of clay minerals results in a further decrease in brittle strength and is attributed to expansion of the brittle field. As plastic strength is influenced by lithology, a large strength contrast can occur across the crust-mantle boundary if deformation is controlled by ductile deformation. Effective elastic thickness for the terrestrial planets calculated from the rheological models indicates its close dependence on spatiotemporal variations in temperature and the presence of water. Although application of the strength models to observed large-scale surface deformational features is subject to large extrapolation and uncertainties, I emphasize the different sensitivity of these features to temperature and water, meaning that quantifying these features (e.g., by data from orbiting satellites or rovers) should help to constrain the internal structure and evolution of the terrestrial planets.
\end{abstract}

Keywords: Strength profile, Rock rheology, Terrestrial planet, Elastic thickness, Thermal gradient, Water

\section{Introduction}

The terrestrial planets typically comprise an outermost rigid layer overlying a convective viscous layer. Although direct subsurface information is not available for these planets, except for Earth, lithospheric structures can be inferred from modeling studies using orbiting satellite data such as multispectral imaging, surface topography, and the gravity field (e.g., Watters and Schultz 2009). The flexural response to surface or subsurface loads is responsible for flexural rigidity and can constrain the

Correspondence: katayama@hiroshima-u.ac.jp

Department of Earth and Planetary Systems Science, Hiroshima University, Higashi-Hiroshima 739-8526, Japan

\section{Springer Open}

thickness of an equivalent elastic plate. By applying simple models incorporating brittle, elastic, and ductile deformation, it is possible to calculate the effective elastic thickness of the lithosphere and its spatial and temporal variations (e.g., Goetze and Evans 1979; McNutt 1984; Watts and Burov 2003). The spacing of faults and fold is also sensitive to the thickness of a strong layer associated with brittle deformation and can therefore provide constraints on lithospheric structure (e.g., Phillips and Hansen 1998; Montesi and Zuber 2003).

Lithospheric structure is controlled mainly by rock strength, which is highly sensitive to temperature (e.g., Ranalli 1992; Kohlstedt et al. 1995). Consequently,

(c) The Author(s). 2021 Open Access This article is licensed under a Creative Commons Attribution 4.0 International License, which permits use, sharing, adaptation, distribution and reproduction in any medium or format, as long as you give appropriate credit to the original author(s) and the source, provide a link to the Creative Commons licence, and indicate if changes were made. The images or other third party material in this article are included in the article's Creative Commons licence, unless indicated otherwise in a credit line to the material. If material is not included in the article's Creative Commons licence and your intended use is not permitted by statutory regulation or exceeds the permitted use, you will need to obtain permission directly from the copyright holder. To view a copy of this licence, visit http://creativecommons.org/licenses/by/4.0/. 
differences in elastic thickness and faults/fold spacing are commonly interpreted to reflect spatiotemporal variations in the vertical thermal gradient in the terrestrial planets. In Earth, the effective elastic thickness of oceanic lithosphere systematically changes with the time of loading, consistent with the plate-cooling model (e.g., Watts et al. 1980). The thickness of the elastic lithosphere within Mars shows spatial variations that are generally correlated with the geological epoch, most likely due to the secular cooling of the planet (e.g., Solomon and Head 1990). Rock strength is also dependent on constituent minerals, meaning that chemical composition, including compositional changes such as the crust to mantle transition, has a substantial influence on the rheological structure of the lithosphere. Because of the large strength contrast across the crust-mantle boundary within Venus, crustal deformation is likely decoupled from the underlying mantle convection, which might have resulted in the absence of plate tectonics on that planet (e.g., Mackwell et al. 1998; Azuma et al. 2014). Another key difference in internal structural features between Venus and Earth is unstable fault motion, whereby the cold and wet lithosphere may facilitate dynamic weakening within Earth, in contrast to stable sliding in the dry and hot lithosphere of Venus (Karato and Barbot 2018).

Recent laboratory experiments have emphasized the influence of water on rock rheology (e.g., Paterson and Wong 2004; Karato 2008). Pore fluid pressure is well known to reduce the brittle strength of rock, and this relationship has been widely applied to enhance recovery of oil and shale gas, as well as to exploit geothermal reservoirs (e.g., Gregory et al. 2011). Earthquakes can be triggered by pore pressure buildup, whereby the temporal evolution of fault strength is likely controlled by fluid accumulation and abrupt fluctuations (e.g., Sibson 1992; Katayama et al. 2012). Another important influence of water on brittle strength is the presence of clay minerals, which has been suggested as a weakening mechanism of fault motions through its markedly low frictional coefficient (e.g., Moore and Lockner 2007). During ductile deformation, the presence of water reduces plastic strength through increasing the number of defects in crystals and promoting mass transfer at grain boundary (e.g., Karato 2008). Nominally anhydrous minerals such as olivine and pyroxene contain very small amounts of water (ppm level), but the dissolved hydrogen in crystals increases the defect concentration, meaning that even trace amounts of water can markedly enhance the rate of plastic deformation (e.g., Karato and Jung 2003; Hirth and Kohlstedt 2003).

This review paper summarizes current knowledge of the rheological properties of crust and mantle materials, including the effects of water on material properties.
Strength profiles of the lithosphere are calculated for Mercury, Venus, Earth, and Mars, which vary in terms of gravity, temperature, and crustal thickness (Fig. 1 and Table 1), following which the implications for the spatiotemporal evolution of the lithosphere of each planet are discussed, focusing particularly on the role of water.

\section{Calculation of strength profiles}

The type of deformation in the interior of rocky planets shifts from brittle deformation at relatively shallow levels to plastic deformation at deeper levels. This is because a fracture surface can easily grow at low temperature and pressure resulting in brittle deformation, whereas at deep levels the fracture surface tends to closes owing to increasing pressure, with plastic deformation becoming dominant as temperature increases with depth. As brittle fracture is commonly restrained by the friction on the existing fault plane, frictional strength is typically used to represent the strength of the brittle region (e.g., Goetze and Evans 1979; Kohlstedt et al. 1995). In the plastic region, strength is calculated using a flow law that is exponentially dependent on temperature. Details of calculating strength for each deformation mechanism and rheological layering are described below.

\subsection{Frictional strength}

Frictional strength is controlled mainly by the applied normal stress on the fault plane, and the friction coefficient is known to be insensitive to lithology and temperature (Byerlee 1978). The strength of the brittle region is generally expressed as follows:

$$
\tau=\mu \sigma_{n}+C
$$

where $\tau$ is shear stress, $\mu$ is the coefficient of friction, $\sigma_{n}$ is normal stress, and $C$ is frictional cohesive strength. The frictional coefficient of 0.85 under low normal stress and typically decreases to 0.6 at higher normal stress were frequently used to calculate the brittle strength (e.g., Kohlstedt et al. 1995). However, recent laboratory experiments and first-principle calculations have shown extremely low the frictional coefficient for clay minerals under wet conditions (e.g., Moore and Lockner 2007; Katayama et al. 2015; Sakuma et al. 2018). In addition to Earth, the presence of clay minerals has been suggested in surficial materials of Mars (e.g., Ehlmann et al. 2011). I therefore calculated brittle strength in the presence of clay minerals for Earth and Mars, using frictional coefficients as low as 0.1 .

Although the frictional strength obtained using Eq. (1) is shear stress, the coordination of stress is typically differential stress in plastic deformation. Therefore, it is necessary to unify the stress components when calculating a strength profile across the brittle-ductile transition. A 


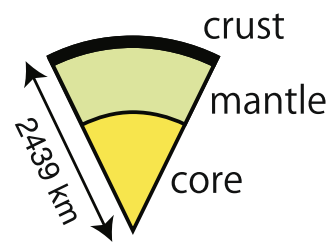

Mercury

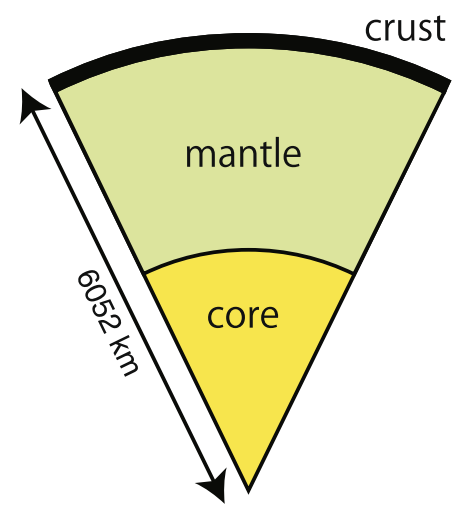

Venus

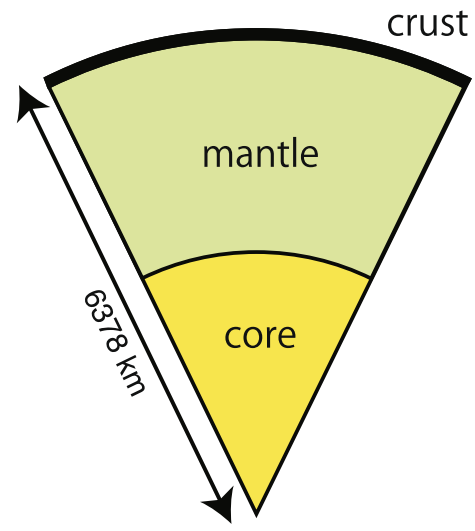

Earth

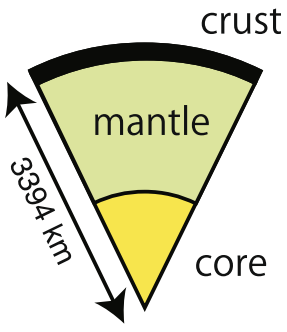

Mars

Fig. 1 Internal structure of the terrestrial planets, composed of crust, mantle, and core

fault plane is generally oriented about $30^{\circ}$ from the maximum principal stress axis, and the frictional strength on the fault plane can be expressed in terms of the principal stress component using this geometrical relationship (Kohlstedt et al. 1995; Katayama and Azuma 2017). In tensional deformation, the maximum principal stress is equivalent to the overburden/lithostatic pressure, whereas the minimum principal stress is equivalent to the pressure during compression; consequently, frictional strength in the tensional field becomes nearly half of that in the compressional field.

In case where pore fluids exist in the brittle region, the pore pressure acts in the direction opposite to the normal stress, so the effective normal stress on the fault plane is calculated as

$$
\sigma_{n}^{\mathrm{eff}}=\sigma_{n}-\alpha P_{p}
$$

where $P_{p}$ is pore fluid pressure, and $\alpha$ is a coefficient that is approximated to unity (e.g., Gueguen and Palciauskas 1994). This relationship indicates that the effective normal stress, and hence the frictional strength, can decrease markedly as pore fluid pressure increases. Here, in the calculation of strength profiles under hydrous conditions, the pore pressure was assumed to be hydrostatic. For the wet model, brittle strength was calculated using Byerlee's law, including the effect of pore fluid pressure. For the clay model, the strength was further decreased on account of the low frictional coefficient.

\subsection{Plastic strength}

In the region of plastic deformation, mechanical strength is strongly influenced by temperature and strain rate, whereas brittle strength is controlled predominantly by pressure. The relationship between strain rate $(\dot{\varepsilon})$ and differential stress $(\sigma)$ is commonly expressed by a powerlaw relationship as follows:

$$
\dot{\varepsilon}=A \frac{\sigma^{n}}{d^{m}} \exp \left(-\frac{E+P V}{R T}\right)
$$

where $A$ is a pre-exponential factor, $d$ is grain size, $E$ is activation energy, $V$ is activation volume, $P$ is pressure, $T$ is temperature and $R$ is the gas constant (e.g., Ranalli 1992; Karato 2008). In this power-law relationship, $n$ and $m$ are constant exponents for stress and grain size, respectively. Plastic deformation is caused by the movement of defects in crystals, in which the dominant deformation mechanism depends on stress, temperature, and grain size, among other factors (e.g., Frost and Ashby 1982). Diffusion creep is controlled by point

Table 1 Basic information for the terrestrial planets

\begin{tabular}{lllll}
\hline & Mercury & Venus & Earth & Mars \\
\hline Semi-major axis $(\mathrm{AU})$ & 0.39 & 0.72 & 1.00 & 1.52 \\
Radius $(\mathrm{km})$ & 2439 & 6052 & 6378 & 3394 \\
Gravity $\left(\mathrm{m} / \mathrm{s}^{2}\right)$ & 3.70 & 8.87 & 9.78 & 3.69 \\
Density $\left(\mathrm{g} / \mathrm{cm}^{3}\right)$ & 5.43 & 5.20 & 5.51 & 3.93 \\
Surface temperature $(\mathrm{K})$ & 440 & 730 & 280 & 220 \\
Crustal thickness $(\mathrm{km})$ & 35 & 15 & 7 & 50 \\
\hline
\end{tabular}


defects, for which the stress and grain size exponents are 1 and 3, whereas dislocation creep is insensitive to grain size and has a strong stress dependence $(n \approx 3)$.

The power-law relationship is frequently used to calculate plastic strength in the lithosphere. However, limitations of the power-law formula have been documented for low temperatures and high stresses (Tsenn and Carter 1987), in which case the strain rate becomes exponentially dependent on stress, as follows:

$$
\dot{\varepsilon}=A \sigma^{2} \exp \left(-\frac{E+P V}{R T}\left(1-\frac{\sigma}{\sigma_{p}}\right)^{2}\right)
$$

where $\sigma_{p}$ is Peierls stress. This mechanism, known as Peierls creep, becomes dominant at depths close to the brittle-ductile transition (e.g., Katayama and Karato 2008). The parameters of flow laws used in the calculations are listed in Table 2.

Another key aspect of plastic deformation is that strength varies with lithology. Plastic strength is generally controlled by the weakest constituent mineral in rock, and the flow laws for plagioclase and olivine are commonly used to calculate plastic strength in the crust and mantle, respectively (e.g., Bürgmann and Dresen 2008). Plastic strength is also dependent on crystal orientation as well as mineral distribution and connectivity, leading to variability in strength (e.g., Yamazaki and Karato 2002); however, isotropic strength was adopted here as the simplest model for rheological calculations.

Water is known to enhance the rate of plastic deformation by increasing the mobility of defects in crystals (e.g., Karato 2008). Although the amounts of water dissolved in nominally anhydrous minerals is minor (ppm level), defect mobility can be increased markedly through distortion in crystals, which enhances plastic deformation (e.g., Karato and Jung 2003; Hirth and Kohlstedt 2003). The influence of water depends on the chemistry of point defects, which varies among minerals and with the mechanism of creep. Plastic strength was calculated for wet models using the flow law determined under fluid-saturated conditions (Table 2).

\subsection{Elastic thickness}

Under applied moments and loads, flexure of the lithosphere occurs on geological time-scales, and the thickness of the elastically responding layer is inferred from the strength envelope of the lithosphere (e.g., Goetze and Evans 1979; McNutt 1984). Here, the effective elastic thickness was calculated following McNutt (1984), with the moment balanced between tensional and compressional forces within the lithosphere. The integrated bending moment of the lithosphere is estimated as

$$
M=\int_{0}^{T_{m}} \sigma(z)\left(z-z_{n}\right) d z
$$

where $T_{\mathrm{m}}$ is the mechanical thickness of the lithosphere, $\sigma(z)$ is the strength at depth $z$, and $z_{\mathrm{n}}$ is the depth of the neutral stress plane. The mechanical thickness is assumed to be represented by the base of the lithosphere, corresponding to the depth with a stress of $<50 \mathrm{MPa}$ (e.g., McNutt 1984). The analytical solution for the bending moment of the lithosphere is expressed as

$$
M=\frac{E K T_{e}^{3}}{12\left(1-v^{2}\right)}
$$

\begin{tabular}{|c|c|c|c|c|c|c|c|}
\hline Rock type & $\begin{array}{l}\text { Creep } \\
\text { mechanism }\end{array}$ & $\begin{array}{l}\text { A } \\
\left(\mathrm{s}^{-1} \mathrm{MPa}^{-\mathrm{n}} \mu \mathrm{m}^{\mathrm{m}}\right)\end{array}$ & $\mathrm{n}$ & $\mathrm{m}$ & $\begin{array}{l}\sigma_{\mathrm{p}} \\
(\mathrm{MPa})\end{array}$ & $\begin{array}{l}\mathrm{E} \\
(\mathrm{kJ} / \mathrm{mol})\end{array}$ & $\begin{array}{l}\text { V } \\
\left(\mathrm{cm}^{3} / \mathrm{mol}\right)\end{array}$ \\
\hline \multirow[t]{3}{*}{ Plagioclase (wet) } & Diffusion creep $^{a}$ & $10^{1.7}$ & 1 & 3 & - & 170 & - \\
\hline & Dislocation creep ${ }^{b}$ & $10^{-5.6}$ & 4 & - & - & 235 & - \\
\hline & Peierls creep ${ }^{c}$ & $10^{-1.2}$ & 2 & - & 3410 & 235 & - \\
\hline \multirow[t]{3}{*}{ Plagioclase (dry) } & Diffusion creep $^{a}$ & $10^{12.1}$ & 1 & 3 & - & 467 & - \\
\hline & Dislocation creep ${ }^{\mathrm{b}}$ & $10^{0.9}$ & 3.9 & - & - & 431 & - \\
\hline & Peierls creep ${ }^{c}$ & $10^{3.5}$ & 2 & - & 9830 & 431 & - \\
\hline \multirow[t]{3}{*}{ Olivine (wet) } & Diffusion creep $^{d}$ & $10^{9.0}$ & 1 & 3 & - & 335 & 4 \\
\hline & Dislocation creep ${ }^{\mathrm{e}}$ & $10^{4.2}$ & 3 & - & - & 410 & 11 \\
\hline & Peierls creep ${ }^{f}$ & $10^{4.3}$ & 2 & - & 2870 & 410 & 11 \\
\hline \multirow[t]{3}{*}{ Olivine (dry) } & Diffusion creep ${ }^{d}$ & $10^{9.2}$ & 1 & 3 & - & 375 & 5 \\
\hline & Dislocation creep & $10^{6.1}$ & 3 & - & - & 510 & 14 \\
\hline & Peierls creep ${ }^{f}$ & $10^{6.3}$ & 2 & - & 9600 & 510 & 14 \\
\hline
\end{tabular}

where $E$ is Young's modulus, $v$ is Poisson's ratio, $K$ is the

Table 2 Flow law parameters used for calculation of rhelogical structures

${ }^{a}$ Rybacki and Dresen (2000), ' Shelton (1981), 'Azuma et al. (2014), dHirth and Kohlstedt (2003), 'Karato and Jung (2003), 'Katayama and Karato (2008)

The rhelogical parameters followed those used by Katayama et al. (2019), except for activation volume, which was given incorrectly in that study 
flexural curvature, and $T_{\mathrm{e}}$ is the effective elastic thickness. The elastic constants of the lithosphere were assumed to be $E=100 \mathrm{GPa}$ and $v=0.25$, and the curvature was set as $5 \times 10^{-7} \mathrm{~m}^{-1}$. The sensitivity of these parameters is discussed in the following sections. As the bending moment of the lithosphere is controlled mainly by the strength close to the brittle-ductile transition, incorporation of Peierls creep provides a large contribution to the estimated elastic thickness.

\section{Rheological models for the terrestrial planets}

In the calculation of strength as a function of depth, lithostatic pressure is calculated using density and gravity for each planet (Table 1). The thermal structure in the terrestrial planets is highly uncertain, so constant thermal gradients ranging from 5 to $20 \mathrm{~K} / \mathrm{km}$ were assumed, corresponding to a surface heat flow of $20-80$ $\mathrm{mW} / \mathrm{m}^{2}$ with a typical thermal conductivity of $4 \mathrm{~W} \mathrm{~m} \mathrm{~m}^{-1}$ $\mathrm{K}^{-1}$ for mantle material. Although the strain rate may vary with location and tectonic processes, a constant strain rate of $10^{-17} \mathrm{~s}^{-1}$ was used to compare the lithospheric strength for the different planets. Variations in strain rate ranging from $10^{-16}$ to $10^{-18} \mathrm{~s}^{-1}$ are shown as dashed lines in Fig. 2 and have a relatively minor influence on the strength profiles. For plastic deformation, grain size was assumed to be $1 \mathrm{~mm}$, resulting in deformation controlled mainly by diffusion creep at the base of lithosphere, with dislocation and Peierls creeps becoming dominant in the middle parts of the lithosphere. Figure 2 shows the calculated strength profiles of oceanic lithosphere within Earth using different thermal gradients under dry and wet conditions. Increasing temperature results in a decrease in plastic strength at depth, and a shallow brittle-ductile transition develops under a high thermal gradient. Water influences lithospheric strength in both the brittle and ductile regions of the terrestrial planets, with the overall strength of the lithosphere decreasing markedly under wet conditions. The presence of clay minerals results in a marked decrease in frictional resistance, and hence the brittle-ductile transition shifts to greater depths (Fig. 2). Figure 3 shows the strength profiles of the planets calculated using a constant thermal gradient of $10 \mathrm{~K} / \mathrm{km}$. Lithospheric strength and the depth of the brittle-ductile transition are highly variable among these different planets, even if a similar thermal structure is assumed.

\subsection{Mercury}

Strength models of Mercury are shown in Fig. 4 with different thermal gradients under dry and wet conditions. Given the relatively small gravity of this planet, the brittle strength is moderate, attributed to a deeper

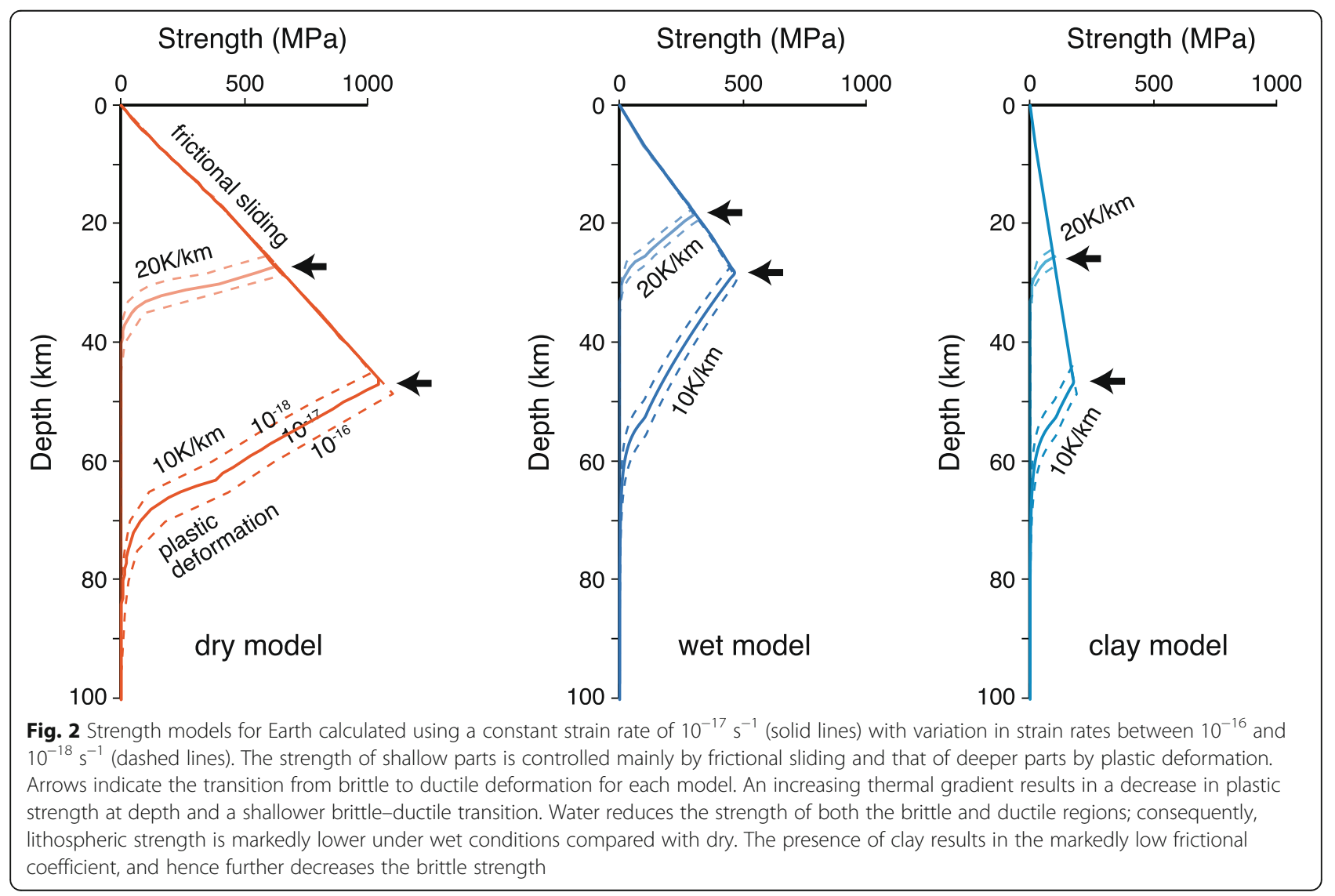



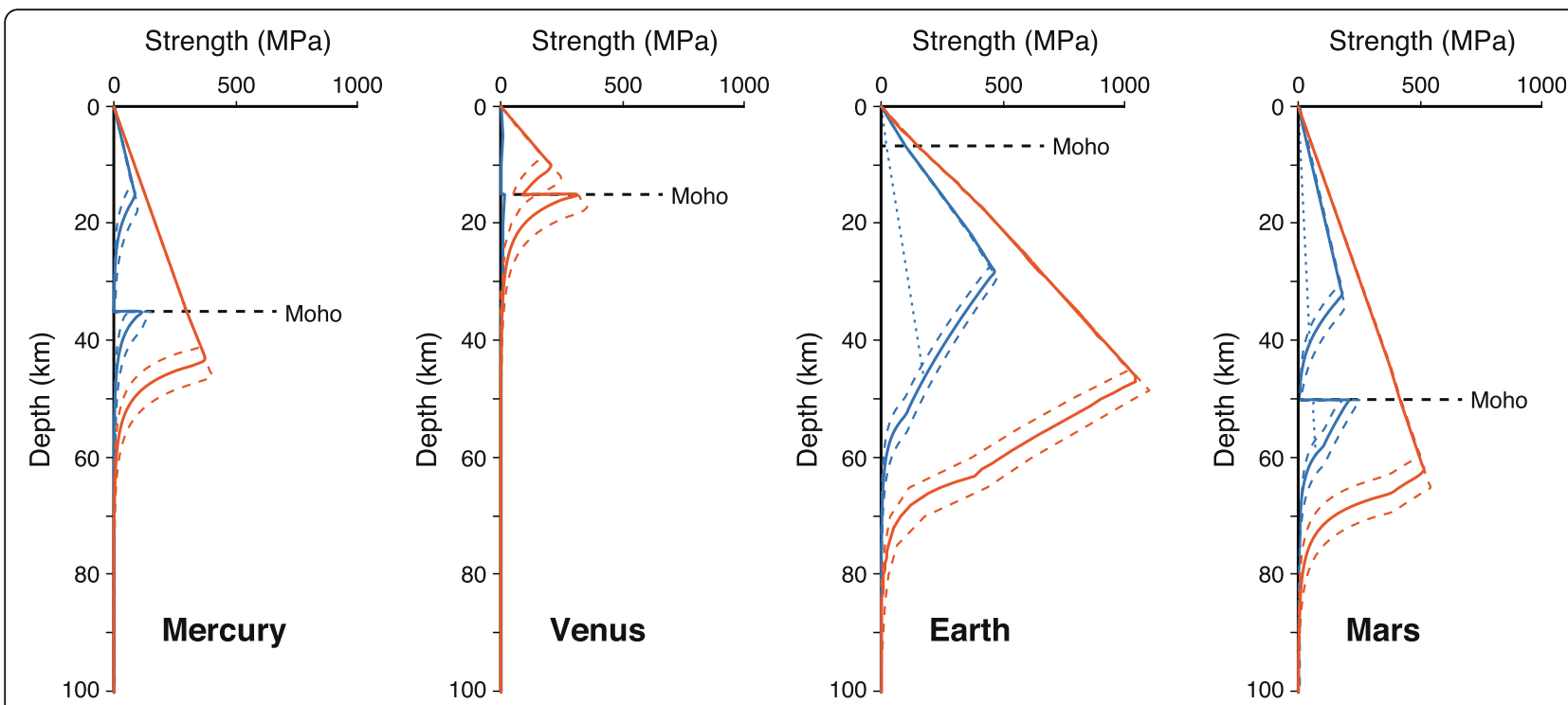

Fig. 3 Strength profiles for Mercury, Venus, Earth, and Mars calculated using a constant thermal gradient of $10 \mathrm{~K} / \mathrm{km}$ and a constant strain rate of $10^{-17} \mathrm{~s}^{-1}$, under both dry (red lines) and wet (blue lines) conditions. Dashed lines indicate the influence of strain rate of $10^{-16}$ and $10^{-18} \mathrm{~s}^{-1}$, and dotted lines indicate the brittle strength in the presence of clay minerals. As plastic strength differs between crust and mantle, the strength profiles show a gap across the crust-mantle boundary (Moho) in case where deformation is plastic

brittle-ductile transition. Increasing the thermal gradient results in a systematic decrease in the plastic strength, and the transition from brittle to ductile deformation occurs at shallower depths. Nimmo and Watters (2004) calculated the depth of the brittle-ductile transition within Mercury with variable crustal thickness and surface heat flow. The present results are mostly consistent with the results of those authors for a given crustal thickness under dry conditions. For wet models, the brittle-ductile transition occurs at shallower depths than those of dry models with a markedly lower transitional strength (Fig. 4). As the plastic strength of plagioclase is weaker than that of olivine, a large strength contrast can be observed across the crustmantle boundary, particularly for a low thermal gradient under wet conditions. A significant weakness in the lower crust may result in mechanical decoupling between crust and mantle, similar to that expected for Venus.

\subsection{Venus}

With a mean surface temperature of $730 \mathrm{~K}$, the overall strength of the Venusian lithosphere is much lower than that of the other terrestrial planets. The rheological model of Venus is also highly dependent on the thermal gradient under dry conditions (Fig. 5), whereas the strength of the lithosphere is very low under wet conditions, meaning that almost the entire lithosphere acts as a viscous layer. Mackwell et al. (1998) presented a strength profile for Venus using the flow of diabase as the crustal material. The difference in the plastic strength between diabase and plagioclase is not significant under deformation controlled by dislocation creep; however, Peierls creep becomes the dominant deformation mechanism near the brittle-ductile transition, and this type of flow law is not available for diabase. Azuma et al. (2014) conducted two-layer experiments with plagioclase and olivine under conditions corresponding to the depth of the crust-mantle boundary within Venus and found that crustal plagioclase is much weaker than mantle olivine. Because of the large strength contrast across the crust-mantle boundary, they suggested that decoupling between crustal deformation and mantle convection likely occurred during the early evolution of Venus.

\subsection{Earth}

Figure 6 shows the calculated strength profiles for oceanic lithosphere within Earth. The thermal structure of oceanic lithosphere is known to have an age dependence (e.g., McKenzie et al. 2005), and the structures calculated for thermal gradients using 10 and $20 \mathrm{~K} / \mathrm{km}$ correspond approximately to oceanic lithosphere with ages of 100 and $20 \mathrm{Ma}$, respectively. As oceanic plate cools with increasing distance from the ocean ridge, the rigidity, and thickness of oceanic lithosphere systematically increase (Fig. 6). Volatile elements are generally depleted in oceanic lithosphere during magmatic differentiations (e.g., Hirth and Kohlstedt 1996), so the dry model is appropriate for the rheological structure. However, recent geophysical observations have suggested extensive hydration along outer-rise bending faults close to the trench (e.g., Obana et al. 2019), which may modify the rigidity of oceanic lithosphere as a hydrous model, giving a weak and 

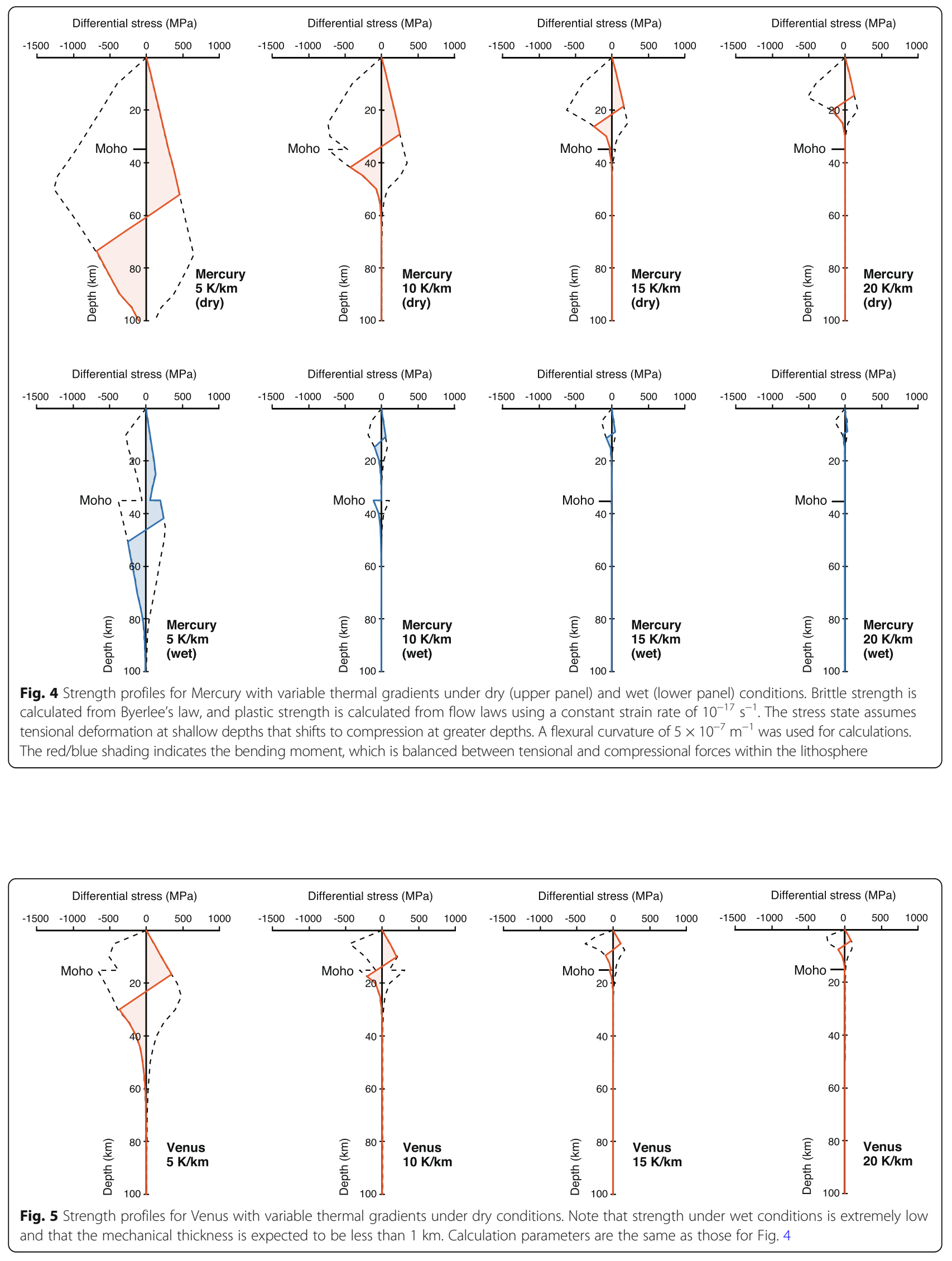


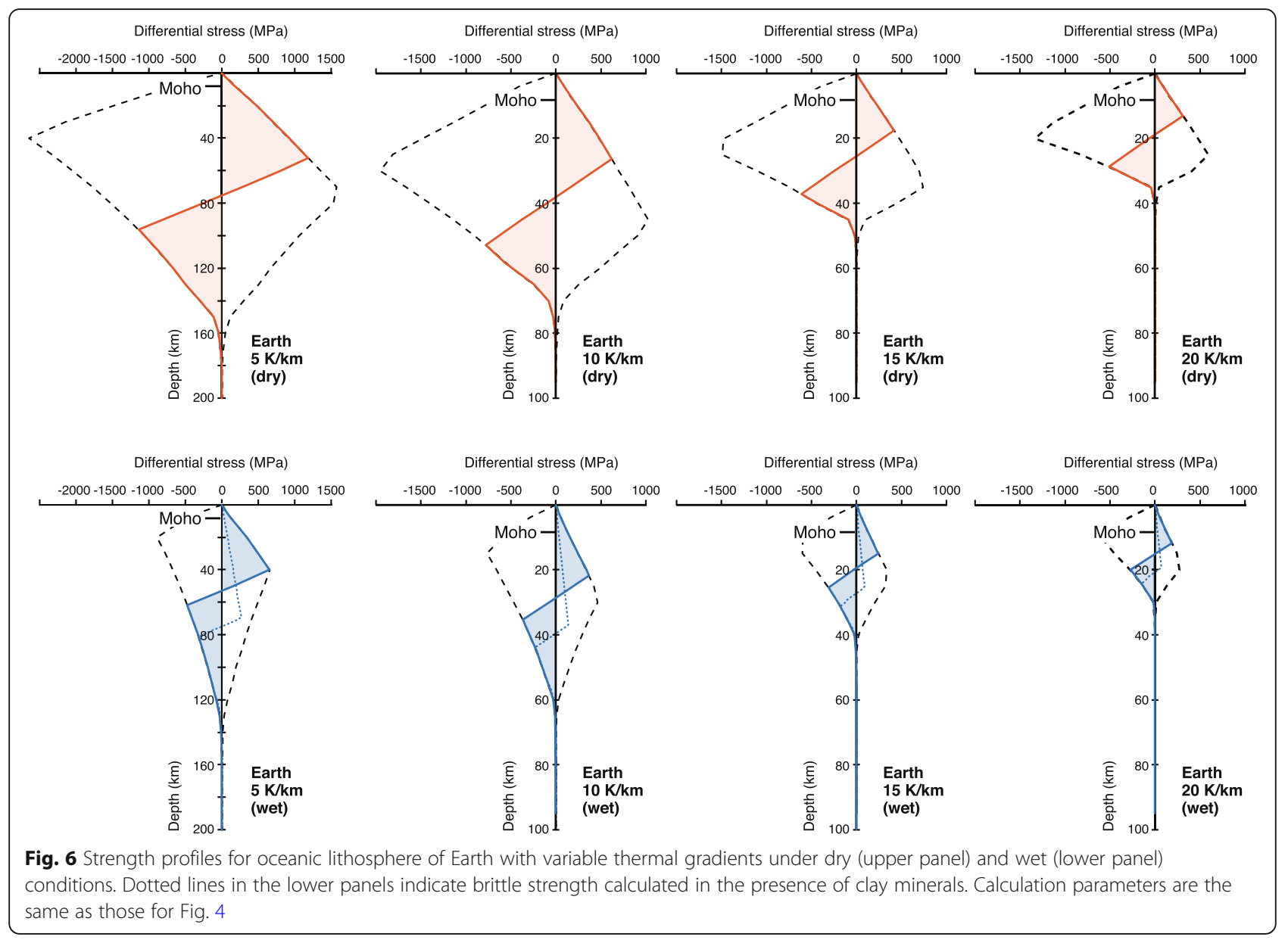

relatively thin elastic layer (Fig. 6). Strength profiles of the continental lithosphere are highly variable, depending on the geotherm, chemical stratification, and the distribution of water (e.g., Burov and Diament 1995). Marked strength layering, such as depicted in the "jelly sandwich" model, results in a weak lower crust and mechanical decoupling at the crust-mantle boundary, whereas the "crème brûlée" model predicts a weak mantle with strength being limited to the crust (e.g., Bürgmann and Dresen 2008). Because of these complexities, strength profiles were calculated only for oceanic lithosphere.

\subsection{Mars}

Strength profiles within Mars for a given thermal gradient are similar to those within Mercury because of the relatively small gravity (Fig. 7). However, surface temperature of the present-day Mars is much cooler than the other terrestrial planets due to the small amounts of solar radiation, indicating a relatively rigid lithosphere. Grott and Breuer (2008) presented strength envelopes for various thermal models including the influence of water, and concluded that rheologically significant amounts of water can be retained in the Martian lithosphere. However, those authors used power-law creep for flow law of plastic deformation, which is not an appropriate mechanism near the brittle-ductile transition, resulting in an overestimation of lithospheric strength. Solomon and Head (1990) calculated the strength profile and elastic thickness incorporating Peierls creep, but the calculations were limited under dry conditions. Considering the Peierls creep and the effect of water, Azuma and Katayama (2017) suggested that a shallow brittle-ductile transition and low lithospheric strength under wet conditions might have changed to a thick and rigid plate owing to depletion of water during the evolution of the lithosphere in Mars. However, if clay minerals are present in shallow parts of the lithosphere, the markedly low frictional coefficient results in a deeper brittle-ductile transition, similar to that calculated for the dry model, whereas the elastic layer is thinner because of the low flexural rigidity.

\section{Discussion}

\subsection{Effects of thermal gradient and water on elastic} thickness and the depth of the brittle-ductile transition The calculated elastic thickness for each terrestrial planet is presented in Fig. 8 as a function of thermal 


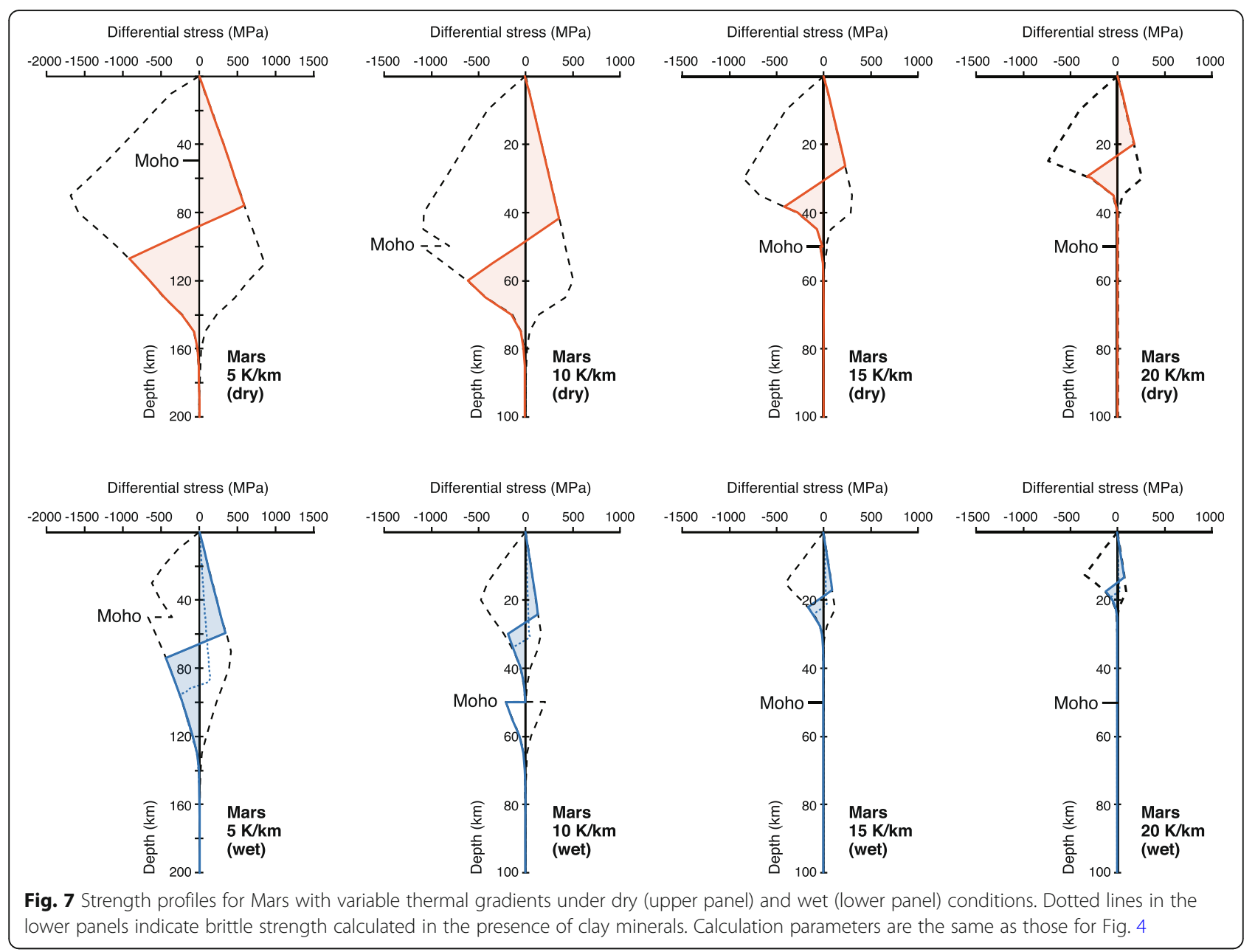

gradient for various models (the values are listed in Table 3). For all planets, a decreasing thermal gradient results in increasing elastic thickness, although the dependencies are slightly different for each planet. I calculated elastic thickness using strain rates ranging from $10^{-16}$ to $10^{-18} \mathrm{~s}^{-1}$, and the variation in strain rate has a relatively minor influence on the estimated elastic thickness (Fig. 8). The calculated elastic thickness under dry conditions for Mercury, Earth, and Mars is highly dependent on thermal gradient, but less so for Venus. This is likely due to the lithospheric strength for Venus being controlled mainly by crustal material properties and less so by temperature (because of the relatively low activation energy for plagioclase). Wet models result in a markedly thin elastic layer, and the presence of clay minerals further decreases lithospheric strength and hence yields a smaller elastic thickness (Fig. 8). It should be noted that for Venus, the calculated elastic thicknesses under wet conditions are smaller than the calculated vertical resolution $(1 \mathrm{~km})$, even at the lowest thermal gradient. Although absolute values carry large uncertainties, as discussed in the following section, the relative changes in elastic thickness with temperature and water are robust.

The depths of the brittle-ductile transition for the terrestrial planets are presented in Fig. 9 as a function of thermal gradient (the values are listed in Table 4). The brittle-ductile transition under dry conditions changes systematically with thermal gradient, whereby a low thermal gradient results in a stiff lithosphere and deeper transition depth. The wet model results in a markedly shallower brittle-ductile transition than those calculated for the dry model, although the presence of clay minerals shows deeper transitional depths than those of wet model (Fig. 9). In the case of Earth and the low thermal gradients for Mars, the brittle-ductile transitions occur at greater depths similar to those of the dry model, as the brittle fields are expanded to mantle depths owing to the low frictional coefficient of clay minerals. In the other cases, significant weakening of wet plagioclase cancels the effect of clay minerals, hence the clay model shows a similar depth of the brittle-ductile transition to that of the wet model at depths below the Moho. 

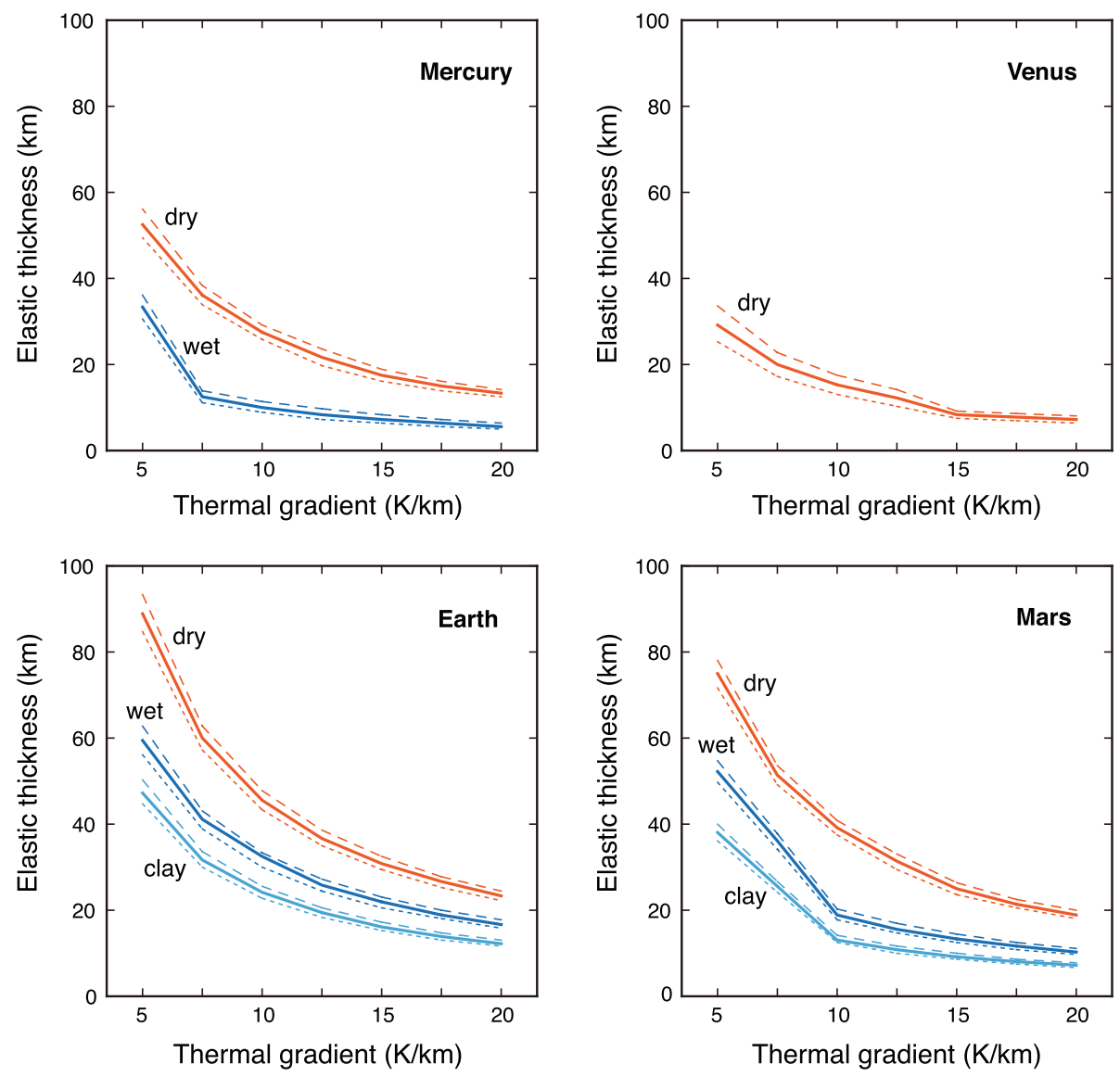

Fig. 8 Effect of thermal gradient on elastic thickness for each planet for various models. Dashed, solid, and dotted lines indicate calculation results using strain rates of $10^{-16}, 10^{-17}$, and $10^{-18} \mathrm{~s}^{-1}$, respectively. In the calculations, a tensional stress field is assumed at shallow depths, which shifts to compression at greater depths. The parameters for the calculations are listed in Tables 1 and 2

Table 3 Elastic thickness $(\mathrm{km})$ calculated using strain-rate of $10^{-17} \mathrm{~s}^{-1}$

\begin{tabular}{|c|c|c|c|c|c|c|c|}
\hline \multirow[t]{2}{*}{ Model } & \multicolumn{7}{|c|}{ Thermal gradient $(\mathrm{K} / \mathrm{km})$} \\
\hline & 5 & 7.5 & 10 & 12.5 & 15 & 17.5 & 20 \\
\hline \multicolumn{8}{|l|}{ Mercury } \\
\hline dry & 52.6 & 36.0 & 27.5 & 21.8 & 17.5 & 15.0 & 13.3 \\
\hline wet & 33.4 & 12.6 & 10.1 & 8.4 & 7.2 & 6.3 & 5.7 \\
\hline \multicolumn{8}{|l|}{ Venus } \\
\hline dry & 29.2 & 19.9 & 15.3 & 12.3 & 8.4 & 7.8 & 7.2 \\
\hline \multicolumn{8}{|l|}{ Earth } \\
\hline dry & 88.8 & 59.9 & 45.5 & 36.7 & 30.8 & 26.6 & 23.4 \\
\hline wet & 59.4 & 41.0 & 32.6 & 25.8 & 22.0 & 19.0 & 16.8 \\
\hline clay & 47.3 & 31.7 & 24.1 & 19.4 & 16.2 & 14.0 & 12.3 \\
\hline \multicolumn{8}{|l|}{ Mars } \\
\hline dry & 74.9 & 51.4 & 39.2 & 31.4 & 24.9 & 21.5 & 19.0 \\
\hline wet & 52.1 & 36.0 & 19.0 & 15.7 & 13.4 & 11.7 & 10.4 \\
\hline clay & 38.0 & 25.5 & 13.2 & 10.9 & 9.2 & 8.0 & 7.1 \\
\hline
\end{tabular}



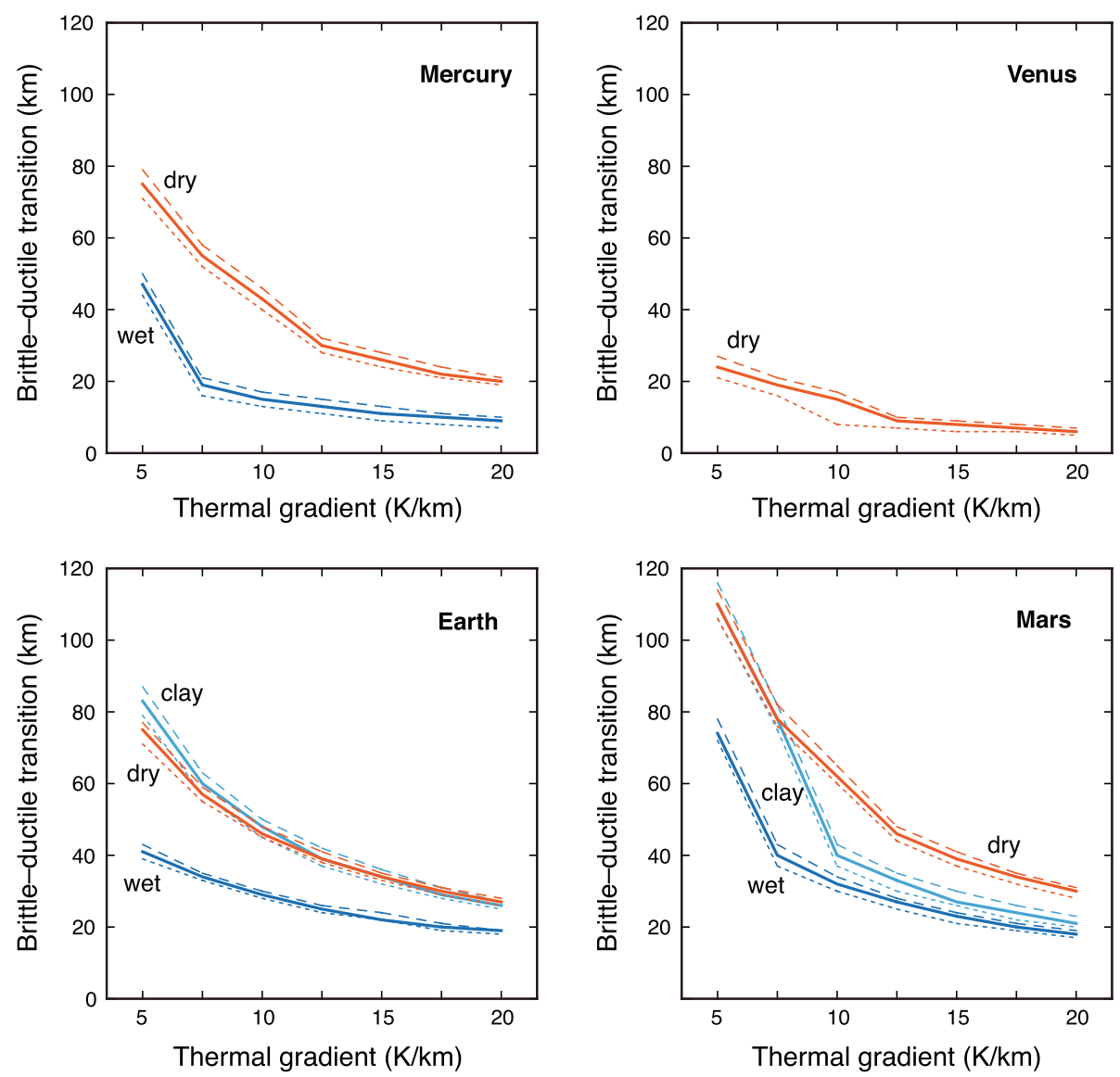

Fig. 9 Effect of thermal gradient on the depth of the brittle-ductile transition in each planet for various models. Dashed, solid, and dotted lines indicate calculation results using strain rate of $10^{-16}, 10^{-17}$, and $10^{-18} \mathrm{~s}^{-1}$, respectively. The tensional stress field is assumed at shallow depths, and the parameters for the calculations are listed in Tables 1 and 2

Table 4 Brittle-ductile transition $(\mathrm{km})$ calculated using strain-rate of $10^{-17} \mathrm{~s}^{-1}$

\begin{tabular}{|c|c|c|c|c|c|c|c|}
\hline \multirow[t]{2}{*}{ Model } & \multicolumn{7}{|c|}{ Thermal gradient $(\mathrm{K} / \mathrm{km})$} \\
\hline & 5 & 7.5 & 10 & 12.5 & 15 & 17.5 & 20 \\
\hline \multicolumn{8}{|l|}{ Mercury } \\
\hline dry & 75 & 55 & 43 & 30 & 26 & 22 & 20 \\
\hline wet & 47 & 19 & 15 & 13 & 11 & 10 & 9 \\
\hline \multicolumn{8}{|l|}{ Venus } \\
\hline dry & 24 & 19 & 15 & 9 & 8 & 7 & 6 \\
\hline \multicolumn{8}{|l|}{ Earth } \\
\hline dry & 75 & 57 & 46 & 39 & 34 & 30 & 27 \\
\hline wet & 41 & 34 & 29 & 25 & 22 & 20 & 19 \\
\hline clay & 83 & 60 & 48 & 39 & 34 & 29 & 26 \\
\hline \multicolumn{8}{|l|}{ Mars } \\
\hline dry & 110 & 78 & 62 & 46 & 39 & 34 & 30 \\
\hline wet & 74 & 40 & 32 & 27 & 23 & 20 & 18 \\
\hline clay & 110 & 78 & 40 & 33 & 27 & 24 & 21 \\
\hline
\end{tabular}



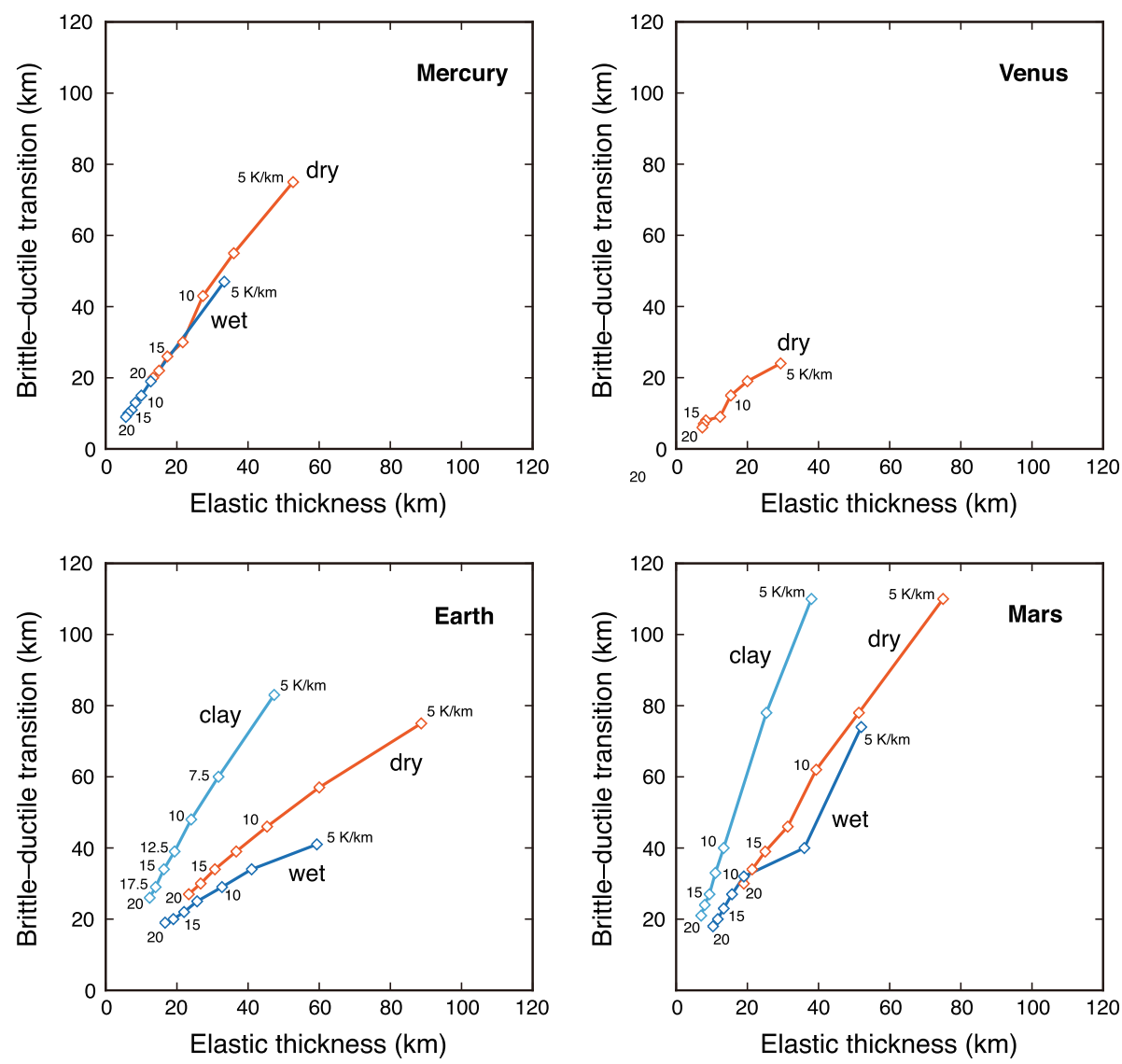

Fig. 10 Relationship between elastic thickness and depth of the brittle-ductile transition in each planet for various models. Calculations were performed using a constant strain rate of $10^{-17} \mathrm{~s}^{-1}$, and the other parameters are the same as those in Figs. 8 and 9 . The values of thermal gradient for the calculations are labeled for each model. The relationship differs among planets and for the presence/absence of water and clay mineral

Consequently, the depth of the brittle-ductile transition for terrestrial planets is not a simple function of thermal gradient, but is highly variable depending on crustal thickness and the presence/absence of water and clay minerals.

The calculated elastic thickness shows a positive relationship with the depth of the brittle-ductile transition for each planet (Fig. 10). The slopes for the dry and wet models are similar, whereas the absolute values differ substantially depending on thermal gradient. A similar positive relationship was found by Nimmo and Watters (2004), even though they used different parameters to those of the present study and a non-linear thermal model. Elastic thickness is controlled mainly by flexural rigidity, whereas the depth of the brittle-ductile transition is insensitive to the stress level, resulting in different sensitivities to thermal gradients and the presence of water. For the clay model, the relationship between elastic thickness and the depth of the brittle-ductile transition is different overall from that of the wet model (Fig. 10). This can be explained by the substantial decrease in flexural rigidity for the clay model, although the brittle field expands to greater depths owing to the low frictional resistance of clay minerals. These different slopes among the dry, wet, and clay models for each terrestrial planet should help to assess the presence of water, if elastic thickness and the depth of the brittle-ductile transition are independently constrained.

Mechanical thickness, measured to the depth corresponding to a strength of $<50 \mathrm{MPa}$, also shows a positive relationship with elastic thickness, with the effective elastic thickness being approximately half of the mechanical thickness. Previous calculations have shown a similar relationship, although the results are highly dependent on flexural curvatures (e.g., McNutt 1984; Solomon and Head 1990). The mechanical boundary layer is sensitive to temperature at the base of the lithosphere, and therefore a constant isotherm of $600{ }^{\circ} \mathrm{C}$ has commonly been used in thermal plate models (e.g., McKenzie et al. 2005). However, plastic strength is efficiently reduced by additional water, meaning that the 
mechanical thickness is also sensitive to the presence of water.

\subsection{Sensitivity and uncertainties}

Using the analytical models of elastic lithosphere presented above, it is possible to capture simplified representations of the lithosphere and calculate its elastic thickness as well as the depth of the brittle-ductile transition. However, the calculations include various uncertainties introduced by the simplifying assumptions made to obtain the strength profiles of the terrestrial planets, as discussed below.

The assumption of a linear thermal gradient is not completely realistic, as thermal conductivity is dependent on temperature and porosity, and the concentration of heatproducing elements are also dependent on chemical compositions. The thermal structure on Earth is known to have a non-linear concave-upward profile (e.g., McKenzie et al. 2005), and therefore the thermal gradient becomes smaller with depth, resulting in a stiffer lithosphere than that calculated using a constant thermal gradient. The thermal conductivity of crust is typically less than that of mantle (e.g., Petitjean et al. 2006), which may also contribute to a non-linear thermal gradient across the crustmantle boundary.

Strain rate is another source of uncertainty in calculations of plastic strength. The strain rate during the deformation of a planet's interior is mostly in the range $10^{-16}$ to $10^{-19} \mathrm{~s}^{-1}$ (e.g., Nimmo and McKenzie 1998), and an average strain rate of $10^{-17} \mathrm{~s}^{-1}$ was used here. This range leads to a large difference in the plastic strength determined by power-law creep; however, if deformation is controlled by Peierls creep, the exponential dependence of strain rate on stress results in a relatively minor influence of strain rate on the plastic strength. Diffusion creep has a relatively minor influence on lithospheric strength if the grain size is larger than $1 \mathrm{~mm}$, although a smaller grain size enhances the rate of diffusion creep and may result in a weaker plastic strength. Grain boundary sliding has been highlighted recently as playing an important role on strain localization (e.g., Hansen et al. 2011). However, this mechanism is predominant between dislocation and diffusion creeps, and has a minor influence on the overall strength of the lithosphere.

Considerable uncertainty in the strength profile can arise from variation in crustal thickness in the terrestrial planets. Plastic strength is dependent on material composition and is therefore sensitive to the crust-mantle boundary, whereas brittle strength is less sensitive to the rock type. Because of the large mineralogical variation in crustal materials, the plastic strength of the crust is less tightly constrained than that of the mantle. This study employed the flow law for plagioclase, which is most likely the weakest major constituent minerals in crustal materials; however, quartz shows a significant hydraulic weakening that may enhance the rate of ductile deformation for silica-rich materials under hydrous conditions (e.g., Paterson 1989). The rheology of clinopyroxene, which exhibits a strength intermediate between plagioclase and mantle olivine, has in some cases been used as an analog for basaltic crust, (e.g., Kirby and Kronenberg 1984).

In the calculation of brittle strength, the frictional coefficient was assumed to be constant. However, chemical reactions may be facilitated along fault zones, where aqueous fluids can penetrate, which might result in the local presence of hydration products such as clay minerals. Spatial scaling of such reaction zones has a marked impact on brittle strength, with interconnected weak zones likely controlling the overall strength of the lithosphere. It is noted that a low frictional coefficient of clay minerals has been reported under fluid-saturated and/or high-humidity environments, but a relatively high frictional coefficient similar to that of Byerlee's law under dry conditions (e.g., Behnsen and Faulkner 2012; Tetsuka et al. 2018). Accordingly, the presence of clay minerals on fluid-saturated fault planes may facilitate frictional sliding and reduce the brittle strength of the lithosphere, whereas drained and dry conditions may cause temporal changes in brittle strength.

For plastic deformation, water-saturated flow laws determined from laboratory experiments at a pressure of 2 GPa were used (e.g., Karato and Jung 2003). However, the influence of water depends on the water contents in crystals, which commonly increases with pressure (e.g., Kohlstedt et al. 1996). Consequently, the influence of water on plastic strength could be underestimated at greater depths and overestimated under conditions of partial saturation. Hydrous minerals such as serpentine may further decrease plastic strength (e.g., Hilairet et al. 2007; Chernak and Hirth 2010). However, the flow law and deformation mechanism of these minerals are still unclear, and further experimental-derived constraints are needed.

Calculation of elastic thickness from a strength profile is highly dependent on flexural curvature. The curvature is commonly inferred from the second derivative of gravity/topography admittance data, which are highly variable even in the same tectonic domain (e.g., McNutt 1984). Bending moments are dominant in those parts of the vertical profile with the maximum strength, so maximum values of curvature have commonly been used for calculations. A constant curvature of $5 \times 10^{-7} \mathrm{~m}^{-1}$ was used here, although it could vary for different features in these planets. Previous modeling have shown that an order of magnitude lower curvature results in a nearly half elastic thickness (e.g., Solomon and Head 1990; Katayama et al. 2019). If the elastic layer is subjected to additional force, the stress state in the lithosphere can 
change. This also causes corresponding changes in the equivalent elastic thickness, but such effects are highly uncertain and were disregarded here.

In contrast to elastic thickness, the depth of the brittle-ductile transition is less sensitive to these parameters and is rather well constrained under a given thermal structures. Brittle strength is dependent on the stress field, whereby the strength calculated for the tensional field is roughly half that for the compressional field, as a result of the lithostatic pressure corresponding to the maximum principal stress in tension. Although it was assumed here that the tensional stress field corresponds to the strength profile, winkle ridge deformation is possibly attributable to shortening and compression, meaning that brittle strength could be doubled in such compressional regions, indicating a shallower transition depth from the brittle to ductile deformation.

\subsection{Internal structure and evolution of the terrestrial planets}

Little is known about the internal structure of Mercury because of limited radar and stereo coverage. One of the few clues for assessing the physical state is the existence of lobate scarps, which likely developed in response to thermal contraction (e.g., Watters et al. 1998). Topographic profiles of the lobate scarps indicate that thrust faulting extended to depths of 30-40 km, corresponding to a lower limit for the brittle-ductile transition (Watters et al. 2002). Assuming the limiting isotherm for Mercury, Watters et al. (2002) suggested a paleo-thermal gradient in the ranges of $3-11 \mathrm{~K} / \mathrm{km}$. Our calculations of the brittle-ductile transition for Mercury are highly dependent on the model used, with $8-10 \mathrm{~K} / \mathrm{km}$ for the dry model and 5-6 $\mathrm{K} / \mathrm{km}$ for the wet model, to explain the observed transition depth. Nimmo and Watters (2004) estimated an effective elastic thickness of $25-30 \mathrm{~km}$ using a yield strength envelope model, similar to the approach taken in the present study. The slope of the brittle-ductile transitional depth and elastic thickness is similar between the dry and wet models (Fig. 10), consistent with the observed relationship, although it is difficult to distinguish these effects in the Mercury's lithosphere. Another estimate using wrinkle ridges in Caloris basin implies an elastic thickness of $\sim 100 \mathrm{~km}$ (Melosh and McKinnon 1988), which far exceeds the thickness inferred from the lobate scarps. As the wrinkle ridge structures were probably formed before the thrust faulting related to the lobate scarps, they cannot be explained by secular cooling (Nimmo and Watters 2004). The discrepancy between the two estimates may reflect a different curvature in these features or the local depletion of water, particularly at the time of the wrinkle ridge formation.

Although there is no clear evidence for plate tectonics on Venus, extensive deformational landforms have been observed on the surface (e.g., Campbell et al. 1984; Zuber and Parmentier 1995). Admittance data from the Magellan mission indicate a long-wavelength range of elastic thickness of $~ 20-30 \mathrm{~km}$ (Barnett et al. 2000), consistent with most previous flexural modeling (Johnson and Sandwell 1994). These estimates are similar to those observed in shields and ancient ocean basins on Earth, although the surface temperature of Venus is much higher than that of Earth, suggesting that the lithosphere of Venus is dry and maintains an elastic core even at the higher temperatures (Barnett et al. 2000). Fault motion is slow and stable under dry conditions, whereas unstable slip and dynamic weakening can occur in fluid-bearing fault zones; hence, the dry lithosphere in Venus might lead to strong plates and promote stagnant lid convection (Karato and Barbot 2018). The dry strength model calculated in the present study requires a thermal gradient of $4-8 \mathrm{~K} / \mathrm{km}$ to explain the observed ranges of elastic thickness in Venus, indicating that these features occurred during the later history of Venus, most likely after global resurfacing events. Using inelastic flexure modeling, Brown and Grimm (1997) calculated thermal gradients as low as $4 \mathrm{~K} / \mathrm{km}$ for Artemis Chasm, a large circular structure in Aphrodite Terra, to account for the absence of flexurally induced faulting and the bending moment of thick lithosphere. In contrast, relatively old surface features such as tessera suggest thinskin tectonics with very short-wavelength features and hence a shallow brittle-ductile transition (Phillips and Hansen 1998). As the brittle-ductile transition is sensitive to temperature gradient, this difference is likely attributable to the internal thermal structures forming these features. The simplest model accounting for these observations is a transition from thin, hot lithosphere during the early history of Venus to thick, cold lithosphere as a result of planetary cooling (e.g., Nimmo and McKenzie 1998). Another possible scenario is hydraulic weakening of crustal rocks during the early history of the planet, as vigorous volcanic activity prior to or during resurfacing may have released substantial amounts of water to the surface. Grinspoon (1993) suggested that the high abundance ratio of deuterium to hydrogen in the atmosphere of Venus can be explained by efficient volcanic outgassing during this period, although this is still an open question.

Plate tectonics on Earth occur as an outermost layer that acts as a mechanically rigid plate that is decoupled from the convecting mantle. Characteristics of the strong outer layer have been determined from lithospheric flexures caused by long-term surface loads such as ice sheets, oceanic islands, and subduction trenches (e.g., Watts and Burov 2003). Although the elastic layer beneath continents is highly variable owing to complex tectonic features, the effective elastic thickness of 
oceanic lithosphere shows a systematic correlation with time of loading (e.g., Watts et al. 1980; Bodine et al. 1981; McNutt 1984). An increase in elastic thickness with age is commonly considered as oceanic lithosphere cools over time and becomes more rigid in its response to surface loading. The depth of the brittle-ductile transition is also related to the age of oceanic lithosphere, as inferred from the lower limit of intraplate earthquakes, consistent with a plate-cooling model (e.g., McKenzie et al. 2005). These mechanical models of oceanic lithosphere allow elastic stresses to be transmitted over large distances and enable the plate to move as a rigid cap above the convecting mantle, bounded by faults at subduction trenches. However, recent detailed modeling of plate flexure beneath the Hawaiian Ridges has shown a large deficit in lithospheric strength using conventional power-law creep (Pleus et al. 2020), and has suggested that the flexural rigidity is controlled mainly by lowtemperature plasticity (Peierls creep), as was calculated in the present study. Although the dry model can mostly account for the observed elastic thickness in the oceanic lithosphere, the thin elastic layer found in several deepsea trenches cannot be explained by this model, possibly because of the weakening due to sea-water penetration into the lithosphere. Seismic reflection and refraction surveys have recently shown low-velocity anomalies even in the oceanic mantle, possibly due to water infiltration along the outer-rise faults (e.g., Fujie et al. 2013). As serpentinite, a product of mantle hydration, is known to be significantly weaker than anhydrous minerals (e.g., Hilairet et al. 2007; Reynard 2013; Hirauchi and Katayama 2015), the plate hydration in these regions is likely responsible for decreasing the thickness of the effective elastic layer.

Various missions to Mars have shown a hemispheric dichotomy in topographic and tectonic features, with the presence of a wide contrast between the high-standing southern hemisphere and the low-lying northern hemisphere (e.g., Zuber 2001). The hemispheric dichotomy is considered to reflect differing crust and mantle structure, whereby crustal thickness in the southern hemisphere is considerably greater than that in the northern hemisphere, except beneath large impact craters (Neumann et al. 2004). Elastic thickness is also correlated with these topographic variations, in which the southern hemisphere exhibits a relatively thin elastic layer (e.g., McGovern et al. 2004). As plastic strength is dependent on lithology, a thick crust can result in weak lithospheric strength owing to the weaker plastic strength of plagioclase compared with olivine, which partly explains the difference in the observed elastic thickness. An extremely thick elastic layer has been reported for the northern polar cap (up to 300 $\mathrm{km}$ ), which may be due to a subchondritic composition in radioactive heat sources or the presence of mantle upwelling in the other regions of Mars (Phillips et al. 2008; Grott et al. 2013). In addition to these compositional variations, the elastic thickness is highly sensitive to internal thermal structures and hence to the time of loading to create the gravitational/topographic anomalies. A low temperature gradient leads to a stiff lithosphere, resulting in a thick elastic layer (Fig. 8), so that the temporal change due to the lithosphere cooling is another important source of variation in elastic thickness (e.g., Solomon and Head 1990; Grott and Breuer 2008; Ruiz et al. 2011). The presence of water and clay minerals can also lead to variation in the elastic thickness, as indicated in our models. The extremely thin elastic thickness of $<10 \mathrm{~km}$ observed in the Noachian terranes, such as Noachis Terra and Terra Cimmeria, can be attributed to a significant amount of water in these relatively old regions, whereby volatile elements might have been incorporated during accretion (e.g., Dreibus and Wänke 1987) or transported by plate subduction during the early evolution of Mars (e.g., Sleep 1994). However, lithospheric stress can change with time owing to viscous relaxation, and caution must be exercised when interpreting these deformational features in old terranes (e.g., Grott et al. 2013). The lateral spacing of wrinkle ridges suggests a rigid lithosphere in the northern hemisphere, where the transition from brittle to ductile deformation occurs at a greater depth than in the southern highlands (Montesi and Zuber 2003). The northern plains are characterized by a relatively thick elastic layer, so the positive correlation between the elastic thickness and the depth of the brittle-ductile transition is consistent with our models shown in Fig. 10. Although Montesi and Zuber (2003) suggested that the difference in the depth of the brittle-ductile transition is associated with the difference of crustal thickness, the appearance of water in the lithosphere can also contribute to the variation of the brittle-ductile transition. One of the main objectives of the on-going InSight mission is to detect Marsquakes and their depth distributions (e.g., Giardini et al. 2020), results of which may help identify the local presence/absence of water in the Martian lithosphere.

\section{Conclusions}

Strength profiles were calculated for the terrestrial planets using a recently updated flow law and considering the effect of water. Using these models, it was possible to constrain the lithospheric strengths of the different planets and to calculate elastic thickness and the depth of the brittle-ductile transition. Although these models present the maximum strength of the rocks, assuming a simple mineralogical stratification and deforming at a constant strain rate, they are useful for explaining the large-scale deformation features captured by surface topographic and gravity data for the terrestrial planets. I suggest that these features are highly sensitive to the thermal gradient as well as the presence of water 
in the lithosphere. Temporal changes in elastic thickness can be explained by secular cooling of planets; however, the extremely thin elastic layer in early Mars cannot be explained by temperature alone and might have been promoted by the presence of water possibly with clay minerals. The relatively shallow brittle-ductile transition within Mercury, as inferred from lobate scarp structures, might also be associated with the local presence of water. Recent orbiting satellite and rover missions have provided data showing various structures and spatiotemporal heterogeneity in deformational features of Mars. Given the sensitivity of the obtained strength models to temperature and water, these data should help to provide a more detailed understanding of the internal structure and evolution of these terrestrial planets.

\section{Acknowledgements}

I thank Shintaro Azuma, Keishi Okazaki, Ken-ichi Hirauchi, and Yhuki Matsuoka for fruitful discussions. Comments from Editors (Shun-ichiro Karato) and two anonymous reviewers greatly improved the paper. I also thank the Nishida prize committee at JpGU for their encouragement to prepare this review article.

\section{Author's contributions}

I.K. conducted the calculations and wrote the manuscript. The author read and approved the final manuscript.

\section{Funding}

This work was supported by JSPS KAKENHI Grant Numbers $18 \mathrm{H} 03733$ and $2 \mathrm{OH} 00200$

\section{Availability of data and materials}

Data sharing is not applicable to this article as no datasets were generated or analyzed during the current study. Please contact the corresponding author for data requests.

\section{Competing interests}

The author declares no competing interests.

Received: 28 June 2020 Accepted: 3 November 2020

Published online: 04 January 2021

\section{References}

Azuma S, Katayama I (2017) Evolution of the rheological structure of Mars. Earth Planets Space 69:8. https://doi.org/10.1186/s40623-016-0593-z

Azuma S, Katayama I, Nakakuki T (2014) Rheological decoupling at the Moho and implication to Venusian tectonics. Sci Rep 4:4403. https://doi.org/10.1038/ srep04403

Barnett DN, Nimmo F, McKenzie D (2000) Elastic thickness estimates for Venus using line of sight accelerations from magellan cycle 5. Icarus 146:404-419. https://doi.org/10.1006/icar.2000.6352

Behnsen J, Faulkner DR (2012) The effect of mineralogy and effective normal stress on frictional strength of sheet silicates. J Struct Geol 42:49-61. https:// doi.org/10.1016/j.jsg.2012.06.015

Bodine J, Steckler H, Watt MS (1981) Observations of flexure and the rheology of the oceanic lithosphere. J Geophys Res 86:3695-3707. https://doi.org/10. 1029/JB086iB05p03695

Brown CD, Grimm RE (1997) Tessera deformation and contemporaneous thermal state of the plateau highlands, Venus. Earth Planet Sci Lett 147:1-10. https://doi.org/10.1016/S0012-821X(97)00007-1

Bürgmann R, Dresen G (2008) Rheology of the Lower Crust and Upper Mantle: Evidence from Rock Mechanics, Geodesy, and Field Observations. Annu Rev Earth Planet Sci 36:531-677. https://doi.org/10.1146/annurev.earth.36.031207. 124326

Burov EB, Diament M (1995) The effective elastic thickness (Te) of continental lithosphere: What does it really mean? J Geophys Res 100:3905-3927. https://doi.org/10.1029/94JB02770
Byerlee J (1978) Friction of rocks. Pure Apply Geophys 116:615-626. https://doi. org/10.1007/BF00876528

Campbell D, Head J, Harmon J, Hine A (1984) Venus: Volcanism and rift formation in Beta Regio. Science 226:167-170. https://doi.org/10.1126/ science.226.4671.167

Chernak L, Hirth G (2010) Deformation of antigorite serpentinite at high temperature and pressure. Earth Planet Sci Lett 296:23-33. https://doi.org/10. 1016/j.epsl.2010.04.035

Dreibus G, Wänke H (1987) Volatiles on Earth and Mars-A comparison. Icarus 71: 225-240. https://doi.org/10.1016/0019-1035(87)90148-5

Ehlmann BL, Mustard JF, Murchie SL, Bibring JP, Meunier A, Fraeman AA, Langevin $Y$ (2011) Subsurface water and clay mineral formation during the early history of Mars. Nature 479:53-60. https://doi.org/10.1038/nature10582

Frost HJ, Ashby MF (1982) Deformation-mechanism maps: The plasticity and creep of metals and ceramics, Oxford: Pergamon Press, p 166.

Fujie G, Kodaira S, Yamashita M, Sato T, Takahashi T, Takahashi N (2013) Systematic changes in the incoming plate structure at the Kuril trench. Geophys Res Lett 40:88-93. https://doi.org/10.1029/2012GL054340

Giardini D et al (2020) The seismicity of Mars. Nature Geoscience 13:205-212. https://doi.org/10.1038/s41561-020-0539-8

Goetze C, Evans B (1979) Stress and temperature in the bending lithosphere as constrained by experimental rock mechanics. Geophys J R 59:463-478. https://doi.org/10.1111/j.1365-246X.1979.tb02567.x

Gregory K, Vidic R, Dzombak D (2011) Water management challenges associated with the production of shale gas by hydraulic fracturing. Elements 7:181-186 https://doi.org/10.2113/gselements.7.3.181

Grinspoon DH (1993) Implications of the high deuterium-to-hydrogen ratio for the sources of water in Venus' atmosphere. Nature 363:428-431. https://doi. org/10.1038/363428a0

Grott M, Breuer D (2008) The evolution of the Martian elastic lithosphere and implications for crustal and mantle rheology. Icarus 193:503-515. https://doi. org/10.1016/j.icarus.2007.08.015

Grott M et al (2013) Long-term evolution of the Martian crust-mantle system. Space Sci Rev 174:49-111. https://doi.org/10.1007/s11214-012-9948-3

Gueguen Y, Palciauskas V (1994) Introduction to the Physics of Rocks. Princeton University Press, Princeton, p 296

Hansen LN, Zimmerman ME, Kohlstedt DL (2011) Grain-boundary sliding in San Carlos olivine: Flow-law parameters and crystallographic-preferred orientation. J Geophys Res 116:B08201. https://doi.org/10.1029/2011JB008220

Hilairet N, Reynard B, Wang Y, Daniel I, Merkel S, Nishiyama N, Petitgirard S (2007) High-pressure creep of serpentine, interseismic deformation, and initiation of subduction. Science 318:1910-1913. https://doi.org/10.1126/ science.1148494

Hirauchi K, Katayama I (2015) Rheological properties of serpentinite and their tectonic significance. J Geography 124:371-396. (in Japanese with English abstract). https://doi.org/10.5026/jgeography.124.371

Hirth G, Kohlstedt DL (1996) Water in the oceanic upper mantle: Implications for rheology, melt extraction and the evolution of the lithosphere. Earth Planet Sci Lett 144:93-108. https://doi.org/10.1016/0012-821X(96)00154-9

Hirth G, Kohlstedt DL (2003) Rheology of the Upper Mantle and the Mantle Wedge: A View from the Experimentalists. Geophys Monogr 138:83-105. https://doi.org/10.1029/138GM06

Johnson CL, Sandwell DT (1994) Lithospheric flexure on Venus. Geophys J Inter 119:627-647. https://doi.org/10.1111/j.1365-246X.1994.tb00146.x

Karato S (2008) Deformation of Earth Materials: An introduction to the rheology of solid Earth., 463 p, Cambridge: Cambridge University Press.

Karato S, Barbot S (2018) Dynamics of fault motion and the origin of contrasting tectonic style between Earth and Venus. Sci Rep 8. https://doi.org/10.1038/ s41598-018-30174-6

Karato S, Jung H (2003) Effects of pressure on high-temperature dislocation creep in olivine. Phil Mag A83:401-414. https://doi.org/10.1080/ 0141861021000025829

Katayama I, Azuma S (2017) Effect of water on rock deformation and rheological structures of continental and oceanic plates. J Geol Soc Japan 123:365-377. (in Japanese with English abstract). https://doi.org/10.5575/geosoc.2017.0019

Katayama I, Karato S (2008) Low-temperature, high-stress deformation of olivine under water-saturated condition. Phys Earth Planet Inter 168:125-133. https://doi.org/10.1016/.pepi.2008.05.019

Katayama I, Kubo T, Sakuma H, Kawai K (2015) Can clay minerals account for the behavior of non-asperity on the subducting plate interface? Prog Earth Planet Sci 2. https://doi.org/10.1186/s40645-015-0063-4 
Katayama I, Matsuoka Y, Azuma S (2019) Sensitivity of elastic thickness to water in the Martian lithosphere. Prog Earth Planet Sci 6. https://doi.org/10.1186/ s40645-019-0298-6

Katayama I, Terada T, Okazaki K, Tanikawa W (2012) Episodic tremor and slow slip potentially linked to permeability contrasts at the Moho. Nature Geo 5:731734. https://doi.org/10.1038/ngeo1559

Kirby SH, Kronenberg AK (1984) Deformation of clinopyroxenite: evidence for a transition in flow mechanisms and semibrittle behavior. J Geophys Res 89: 3177-3192. https://doi.org/10.1029/JB089iB05p03177

Kohlstedt D, Evans B, Mackwell S (1995) Strength of the lithosphere: Constraints imposed by laboratory experiments. J Geophys Res 100:17587-17602. https://doi.org/10.1029/95JB01460

Kohlstedt DL, Keppler H, Rubie DC (1996) Solubility of water in the $a, \beta$ and $\gamma$ phases of $(\mathrm{Mg}, \mathrm{Fe})_{2} \mathrm{SiO}_{4}$. Contrib Mineral Petrol 123:345-357. https://doi.org/ $10.1007 / \mathrm{s} 004100050161$

Mackwell S, Zimmerman M, Kohlstedt D (1998) High-temperature deformation of dry diabase with application to tectonics on Venus. J Geophys Res 103:975984. https://doi.org/10.1029/97JB02671

McGovern PJ, Solomon SC, Smith DE, Zuber MT, Simons M, Wieczorek MA Phillips RJ, Neumann GA, Aharonson O, Head JW (2004) Correction to "Localized gravity/topography admittance and correlation spectra on Mars: Implications for regional and global evolution". J Geophys Res 107:5418. https://doi.org/10.1029/2004JE002286

McKenzie D, Jackson J, Priestley K (2005) Thermal structure of oceanic and continental lithosphere. Earth Planet Sci Lett 233:337-349. https://doi.org/10. 1016/j.epsl.2005.02.005

McNutt MK (1984) Lithospheric Flexure and Thermal Anomalies. J Geophys Res 89:11180-11194. https://doi.org/10.1029/JB089iB13p11180

Melosh HJ, McKinnon WB (1988) The tectonics of Mercury. Mercury, edited by Vilas F, Chapman CR, Matthews MS. University of Arizona Press, Tucson, pp $374-400$

Montesi LG, Zuber MT (2003) Clues to the lithospheric structure of Mars from wrinkle ridge sets and localization instability. J Geophys Res 108:5048. https://doi.org/10.1029/2002JE001974

Moore DE, Lockner DA (2007) Friction of the smectite clay montmorillonite. The Seismogenic Zone of Subduction Thrust Faults, edited by Dixon T, Moore C. Columbia Univ. Press, New York, pp 317-345

Neumann GA et al (2004) Crustal structure of Mars from gravity and topography. J Geophys Res 109:E08002. https://doi.org/10.1029/2004JE002262

Nimmo F, McKenzie D (1998) Volcanism and tectonics on Venus. Annu Rev Earth Planet Sci 26:23-51. https://doi.org/10.1146/annurev.earth.26.1.23

Nimmo F, Watters TR (2004) Depth of faulting on Mercury: implications for heat flux and crustal and effective elastic thickness. Geophys Res Lett 31:L02701. https://doi.org/10.1029/2003GL018847

Obana K, Fujie G, Takahashi T, Yamamoto Y, Tonegawa T, Miura S, Kodaira S (2019) Seismic velocity structure and its implications for oceanic mantle hydration in the trench-outer rise of the Japan Trench. Geophys J Int:16291642. https://doi.org/10.1093/gji/ggz099

Paterson MS (1989) The interaction of water with quartz and its influence in dislocation flow-an overview. In: Karato S, Toriumi M (eds) Rheology of Solids and of the Earth. Oxford Univ. Press, New York, pp 107-142

Paterson MS, Wong T (2004) Experimental Rock Deformation, The Brittle Field. Springer-Verlag, New York, p 347

Petitjean S, Rabinowicz M, Grégoire M, Chevrot S (2006) Differences between Archean and Proterozoic lithospheres: Assessment of the possible major role of thermal conductivity. Geochem Geophys Geosyst 7:Q03021. https://doi. org/10.1029/2005GC001053

Phillips RJ, Hansen VL (1998) Geological evolution of Venus: Rises, plains, plumes, and plateaus. Science 279:1492-1497. https://doi.org/10.1126/science.279. 5356.1492

Phillips RJ et al (2008) Mars north polar deposits: Stratigraphy, age, and geodynamical response. Science 320:1182-1185. https://doi.org/10.1126/ science.1157546

Pleus A, Ito G, Wessel P, Frazer LN (2020) Rheology and thermal structure of the lithosphere beneath the Hawaiian Ridge inferred from gravity data and models of plate flexure. Geophys J Inter 222:207-224. https://doi.org/10. 1093/gji/ggaa155

Ranalli G (1992) Rheology of the Earth, 409 p, London: Chapman and Hall.

Reynard B (2013) Serpentine in active subduction zones. Lithos 178:171-185. https://doi.org/10.1016/j.lithos.2012.10.012
Ruiz J, McGovern PJ, Jimenénez-Díaz A, López V, Williams JP, Hahn BC, Tejero R (2011) The thermal evolution of Mars as constrained by paleoheat flows. Icarus 215-508-517. https://doi.org/10.1016/j.icarus.2011.07.029.

Rybacki E, Dresen G (2000) Dislocation and diffusion creep of synthetic anorthite aggregates. J Geophys Res 105:26017-26036. https://doi.org/10.1029/ 2000JB900223

Sakuma H, Kawai K, Katayama I, Suehara S (2018) What is the origin of macroscopic friction? Science Advances 4. https://doi.org/10.1126/sciadv. aav2268

Shelton GL (1981) Experimental deformation of single phase and polyphase crustal rocks at high pressures and temperatures. Providence: PhD thesis, Brown University.

Sibson RH (1992) Implications of fault-valve behavior for rupture nucleation and recurrence. Tectonophys 211:283-293. https://doi.org/10.1016/00401951(92)90065-E

Sleep NH (1994) Martian plate tectonics. J Geophys Res 99:5639-5655. https://doi. org/10.1029/94JE00216

Solomon SC, Head JW (1990) Heterogeneities in the thickness of the elastic lithosphere of Mars: Constraints on heat flow and internal dynamics. J Geophys Res 95:11073-11083. https://doi.org/10.1029/JB095iB07p11073

Tetsuka H, Katayama I, Sakuma H, Tamura K (2018) Effects of humidity and interlayer cations on the frictional strength of montmorillonite. Earth Planet Space 70:56. https://doi.org/10.1186/s40623-018-0829-1

Tsenn MC, Carter NL (1987) Upper limits of power law creep in rocks. Tectonophys 136:1-26. https://doi.org/10.1016/0040-1951(87)90332-5

Watters T, Schultz R (2009) Planetary Tectonics. Cambridge University Press. https://doi.org/10.1017/CBO9780511691645

Watters TR, Robinson MS, Cook AC (1998) Topography of lobate scarps on Mercury: new constraints on the planet's contraction. Geology 26:991-994. https://doi.org/10.1130/0091-7613

Watters TR, Schultz RA, Robinson MS, Cook AC (2002) The mechanical and thermal structure of Mercury's early lithosphere. Geophys Res Lett 29:1542. https://doi.org/10.1029/2001GL014308

Watts AB, Bodine JH, Steckler MS (1980) Observations of flexure and the state of stress in the oceanic lithosphere. J Geophys Res 85:5369-6376. https://doi. org/10.1029/JB085iB11p06369

Watts $A B$, Burov EB (2003) Lithospheric strength and its relationship to the elastic and seismogenic layer thickness. Tectonophys 213:113-131. https://doi.org/ 10.1016/S0012-821X(03)00289-9

Yamazaki D, Karato S (2002) Fabric development in (Mg,Fe)O during large strain, shear deformation: Implications for seismic anisotropy in Earth's lower mantle. Phys Earth Planet Int 131:251-267. https://doi.org/10.1016/500319201(02)00037-7

Zuber M, Parmentier E (1995) Formation of fold-and-thrust belts on Venus by thick-skinned deformation. Nature 377:704-707. https://doi.org/10.1038/ $377704 \mathrm{a} 0$

Zuber MT (2001) The crust and mantle of Mars. Nature 412:220-227. https://doi. org/10.1038/35084163

\section{Publisher's Note}

Springer Nature remains neutral with regard to jurisdictional claims in published maps and institutional affiliations.

\section{Submit your manuscript to a SpringerOpen ${ }^{\circ}$ journal and benefit from:}

- Convenient online submission

- Rigorous peer review

- Open access: articles freely available online

High visibility within the field

- Retaining the copyright to your article

Submit your next manuscript at $>$ springeropen.com 